\title{
Continuity of care for patients with malignant disease
}

\author{
L. A. M. WILLS* \\ M.Sc., M.B., M.R.C.P.
}

King Edward VII Hospital, Midhurst, Sussex GU29 OBL

\begin{abstract}
Summary
The first year of running a new Continuing Care Unit for patients with malignant disease demonstrated the jmportance of continuity of care in their management after curative measures have ceased to be appropriate. This was achieved by regular home visiting by Unit staff, liaison with home care services and the promise of readmission whenever necessary. As a consequence good relationships with patients, relatives and community services were built up, the average duration of in-patient stay was reduced to $\mathbf{1 9 . 6}$ days and more effective episode care was possible, this being integrated with an understanding of the overall problem.
\end{abstract}

\section{The unit}

A five bedded unit for the care of patients with incurable malignant disease was opened on January 1st, 1976, under the auspices of the National Society for Cancer Relief, a charitable body which was founded in 1911 and which is setting up Macmillan Units for Continuing Care throughout the country. This Unit consisted of single rooms at one end of an acute medical ward in King Edward VII Hospital, Midhurst, West Sussex. More than five rooms could be and often were used if necessary. The Society and the Hospital both subsidized the Unit.

A part time Medical Officer undertook the care of the in-patients and organized home visiting, under the supervision of two consultant physicians in the Hospital. Two part time staff nurses were appointed, to work under the direction of the existing ward sister on the ward which was used. Weekly case discussions were held, and were attended by the Hospital Social Worker. None of the Unit staff had prior experience in the field of Continuing Care, and advice from and visits to established centres such as St Christopher's Hospice in Sydenham, London, proved most valuable. Referring oncologists visited patients frequently and were always willing to advise on management.

The emphasis was placed on the alleviation of pain and other distressing symptoms, a homely atmosphere with open visiting, palliative procedures

\footnotetext{
* Present address: Department of Medicine, Aberdeen Royal Infirmary, Foresterhill, Aberdeen AB9 2ZD.
}

rather than inappropriate investigations or treatments, and the continuity of care provided by regular home visits. Telephone contact was also used to provide support, patients often just wanting a reassuring chat about symptoms or medication, and they were encouraged to call the Unit from time to time. The great distance from the hospital which was often involved made very frequent visits to some patients less feasible than originally hoped.

Referral visits were carried out whenever possible, to assess the patient and the home situation and to allow the patient to meet the Unit staff before coming into hospital. Follow-up visiting was done by the doctor or nurses, and occasionally the social worker and a voluntary visitor.

The catchment area was the whole of West Sussex, part of South-West Surrey and part of Wessex. Only patients with malignant disease were admitted as it was not the purpose of this Unit to accept long stay chronic sick people, in view of the very small number of beds available, at least in the initial period.

\section{Results}

During the first year of running, seventy-seven patients were referred and of these seventy-one were accepted. Of these, forty-seven were women, there were twenty-three men and one child. Considering that the prevalence of malignant disease in the area is estimated at roughly 7000 cases, it is evident that only $1 \%$ of possible patients was seen.

There were sixty admissions, thirteen people coming in more than once and one person five times. There were thirty-nine discharges, and forty deaths in the ward, with six deaths at home. Most people were referred by their general practitioners, and one half lived more than 20 miles from the hospital. The mean duration of in-patient stay fell from 23 days for the first six months to $\mathbf{1 9 . 6}$ days overall, the median stay being 15 days. Carcinoma of the breast was the commonest primary seen, followed by large bowel and lung. The mean age for men was 65 years, and for women, 64 years.

Altogether 2518 miles were covered in visits during the year, including some bereavement visits to relatives felt to be at especial risk. Patients seen at 


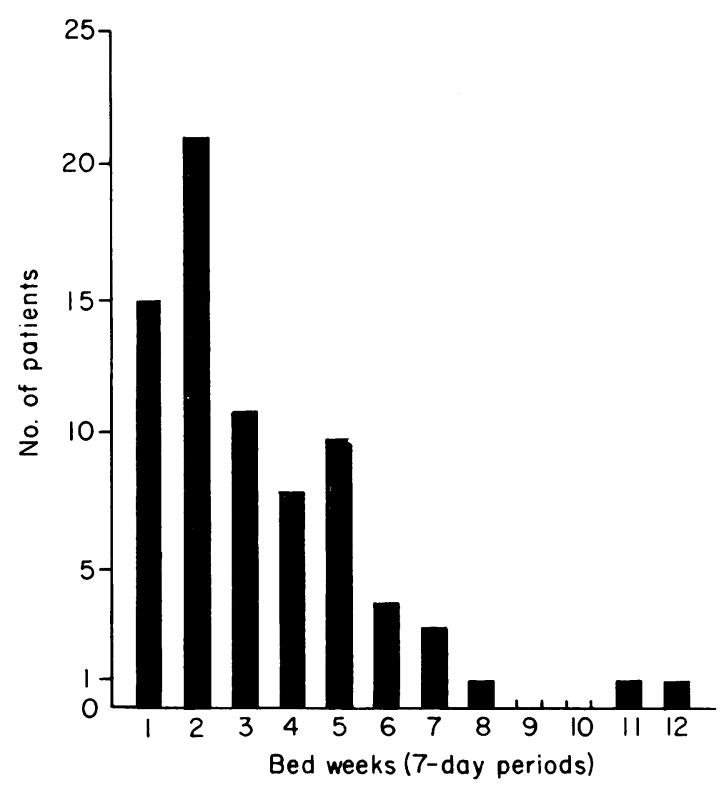

Fig. 1. Chart showing duration of in-patient stay.

home could be reassured about entering hospital, their potential ability to cope again on discharge could be assessed, relatives met and good liaison with community nurses and practitioners established. It was encouraging for patients to see the same staff at home and in hospital, relieving some of the fears of going into hospital by ensuring that they saw a familiar face on arrival there.

Patients were often surprised that the hospital should continue to take an interest in them after discharge to the extent of visiting them at home, and were most appreciative. They were more liable to discuss their fears, outlook or treatment in the more natural and relaxed atmosphere of their own homes, and the Unit staff were fortunate in that they had rather more time to spend with them than would a busy practitioner, district nurse or outpatient clinic staff. Relatives were more likely to cope at home for a longer time if they were assured of the possibility of admission at any time, and they also welcomed a chance to ask questions. There were often quite trivial worries which might have become magnified if relatives had not had the safety valve of discussing them.

It was found that although these visits were time consuming and often emotionally draining, they were extremely worth-while in terms of effective patient care and comfort. Medical and nursing procedures were not usually carried out, the Unit staff in no way superseding the community care services. However, the adequacy of medication particularly for pain could be assessed and its appropriate use on a regular basis could be emphasized, many patients and indeed some doctors and nurses not appreciating the importance of maintaining a constant level of analgesia so as to anticipate pain rather than attempt to control it when severe.

At these visits, too, potential problems could often be averted by sympathetic discussion, and a breakdown in the situation could sometimes be anticipated, allowing for admission to be arranged ahead. Short-term admissions for the relief of symptoms, for specialized procedures such as cytotoxic chemotherapy or spinal blocks, to give the relatives a much needed rest, or for terminal nursing care were the aim of the Unit. Once people became reassured about continuity of care and readmission, and when practitioners came to understand the purpose of the Unit, the aim was achieved in most cases. This allowed many patients to enjoy more time at home than they might have done without this policy, and also made for more effective use of the available beds. Some patients were able to remain at home until they died, support and occasionally medication being provided by the Unit.

As others have shown before them (Saunders, 1967, 1973, 1976; Twycross, 1974) the Unit staff were able to show that the pain of terminal malignant disease was almost always controllable safely bx adequate, regular doses of suitable analgesics Pain is therefore an unnecessary burden for these patients. In fact, as was also found by Hinton (1973), only $50 \%$ of the patients considered pain to be a problem. Some of these were managed satisfactorily on paracetamol or Distalgesic (paracetamol with dextropropoxyphene), progressing if necessary to dihydrocodeine or Diconal (dipipanone with cyclizine). Oxycodone sometimes helped, but pethidine and dextromoramide were found to be of too short a duration of action and strongly addictive, being therefore unsuitable in chronic terminal pain.

Oral diamorphine was used in 46 patients at some time during their illness, usually in doses of 5 or 10 mg every $4 \mathrm{hr}$, although if higher doses were needed they were used without hesitation and with no problems of drowsiness, tolerance or dependence. One man was able to get up and dressed for the first time in many weeks on $80 \mathrm{mg}$ every $3 \mathrm{hr}$, and went home for 10 weeks on this dose. When pain was properly controlled patients were generally more alert, and quality of life was greatly improved. Often the opiate was only needed temporarily, and there was then no problem in changing to weaker analgesics, but if it was needed on a long-term basis, there was no evidence of tolerance provided the correct dose was found and taken regularly.

A phenothiazine was normally given with the diamorphine, to potentiate its effect and to counteract 


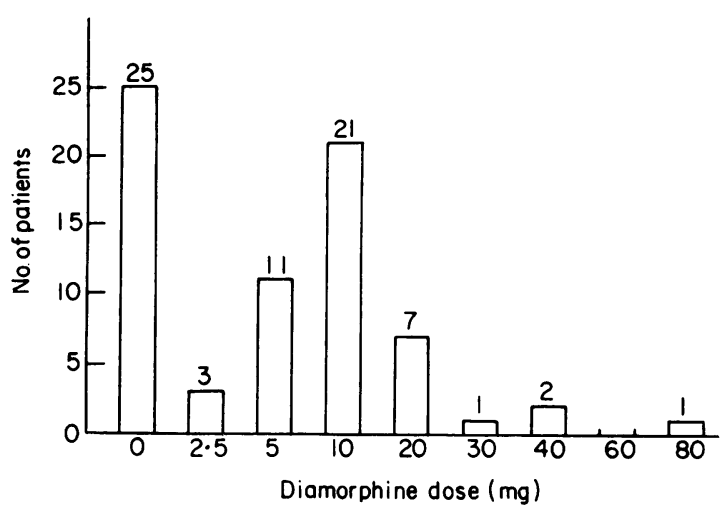

FIG. 2. Histogram of maximum doses of diamorphine used.

nausea. Syrup and alcohol were not added, but cocaine sometimes was. Parenteral administration of analgesics was rarely needed before the final $48 \mathrm{hr}$ of life. Diamorphine was not only used for pain relief, but also for euphoriant action and to relieve distressing dyspnoea, in small doses.

Conversations with patients about their illness were found to be held rather more naturally than is the case on some acute wards, the atmosphere being less pressurized or cure-orientated. If patients really wanted to know the truth, and were met with prevarication or conflicting statements, they tended to become withdrawn, lonely and distrustful of staff. An honest, compassionate discussion of the facts, to the extent that they wished to know them and in such a way as not to destroy all hope, often eased their fears and loneliness considerably. On the other hand, supplying gratuitous information sometimes caused depression and a tendency to give up altogether. It was generally found more satisfactory for the relatives and the patient to share the knowledge if possible. These conversations were never easy, and their extent and timing depended very much on individual patients. It was found to be wiser and more courteous to get to know the patient as a person before embarking on such discussions with him. This inevitably involved time, and caring involvement.

It was the policy to encourage any member of the team to have such talks with patients, not just the doctor, and to enter a comment to that effect in the case notes. The Unit staff met frequently to ensure that everyone knew what had been said or asked. Many patients became more peaceful when they knew the truth, but some never asked, in which case their privacy was respected and their dignity preserved. The impression was that most dying patients were aware of their condition, even though they might not wish to speak of it, being content with a tacit understanding between themselves and staff.
This was also found by Glaser and Strauss (1965). Many people had more courage than the staff had credited them with, or indeed had had themselves.

The staff learnt to recognize that when patients whom they had come to know well eventually died, they suffered a sense of bereavement and needed to go through a period of mourning. They were able to help each other as a team by sharing their own grief and distress at suffering and death which they could not prevent. The grief of relatives could be shared, too, with members of the caring team, and bereavement visits carried out.

\section{Discussion}

The principles of symptom relief in malignant disease, pioneered largely in special hospices, can be employed equally effectively by a small team with no prior experience or special expertise in the field. The hardest suffering to alleviate was mental anguish, particularly that of parents leaving young children. In the experience of the team, a willingness to become involved and to care was of far more help to distressed patients and their families than the giving of antidepressants.

It seems there is no substitute for getting involved, and this will inevitably mean getting hurt sometimes. For this reason the author feels that the smooth running of such units depends on a close-knit team approach, and a high staff to patient ratio with mainly mature, part time staff who have strong outside interests. The burden of care is then shared, over-involvement avoided and grief understood, accepted and come to terms with.

A small continuing care unit run by a team of committed people who are willing to get involved, to be adaptable and to go into the community can be a valuable and efficient addition to the services for patients with incurable cancer. It has the unique ability to co-ordinate community and hospital based services, so allowing for a more flexible and appropriate admissions policy for episode care to evolve. In this way the fullest possible use of available beds can be made, and pressure on acute beds relieved since many patients are enabled to spend more time at home during their final illness, which represents a significant saving on expensive in-patient facilities. Cancer is the second major cause of death in developed countries, so this saving is not inconsiderable.

These patients are better managed in a special unit with its quieter, more home-like atmosphere where their particular needs may be concentrated on and they may be supported more effectively. The home follow-up provides continuity of care and assures them of continued interest in them by the hospital staff. 


\section{Acknowledgments}

This work was supported by the National Society for Cancer Relief. I would like to express thanks to the medical, nursing and administrative staff of the King Edward VII Hospital, and the Midhurst Medical Research Institute, as well as to all those who referred patients to the unit. My greatest debt of admiration and gratitude is to the patients themselves, and their relatives.

\section{References}

SAUNDERs, C. (1967) The Management of Terminal Illness. Hospital Medicine Publications, London.
SAUnders, C. (1973) Terminal care. In: Medical Oncology (Ed. Bagshawe, K.D.). Blackwell Scientific Publications, Oxford. (Reprinted by St Christopher's Hospice, London.)

SAUNDERS, C. (1976) Control of pain in terminal cancer. Nursing Times, July 22, p. 1133.

TwYCRoss, R.G. (1974) Clinical experience with diamorphine in advanced malignant disease. International Journal of Clinical Pharmacology, 93, 184.

HinToN, J. (1973) Bearing cancer. British Journal of Medical Psychology, 46, 105.

Glaser, B.G. \& Strauss, A.L. (1965) Awareness of Dying. Aldine Publishing Co., Chicago. 